\title{
Correction to: Four Decades of Organic Anthropogenic Pollution: a Compilation for Djerdap Lake Sediments, Serbia
}

\author{
L. Hagemann • Milica Kašanin-Grubin $(\mathbb{D})$ - Gordana Gajica $(\mathbb{D})$ - Snežana Štrbac $(\mathbb{D}$ • \\ Aleksandra Šajnović $(\mathbb{D}) \cdot$ Branimir Jovančićević $(\mathbb{D})$ - Nebojša Vasić • Jan Schwarzbauer (D)
}

Published online: 31 January 2020

(C) Springer Nature Switzerland AG 2020

\section{Correction to: Water Air Soil Pollut (2019) 230: 246 https://doi.org/10.1007/s11270-019-4277-8}

The original version of this article unfortunately contained an error.

The authors missed to mention that this project received financial support by the Ministry of Education, Science and Technological Development of the Republic of Serbia, Grants 176006, 176019.

In addition, the Figure 1 was published erroneously. The corrected Figure 1 is shown below.

The online version of the original article can be found at https://doi.org/10.1007/s11270-019-4277-8

L. Hagemann · J. Schwarzbauer $(\bowtie)$

Energy and Mineral Resources Group (EMR), Institute for Geology and Geochemistry of Petroleum and Coal, RWTH Aachen University, 52058 Aachen, Germany e-mail: jan.schwarzbauer@emr.rwth-aachen.de

M. Kašanin-Grubin · G. Gajica · S. Štrbac • A. Šajnović Institute of Chemistry, Technology and Metallurgy, Center of Chemistry, University of Belgrade, Studentski trg 12-16, Belgrade 11000, Serbia

B. Jovančićević

Faculty of Chemistry, University of Belgrade, Studentski trg 12 16, Belgrade 11000, Serbia

N. Vasić

Faculty of Mining and Geology, University of Belgrade, Đušina 7, Belgrade 11000, Serbia 


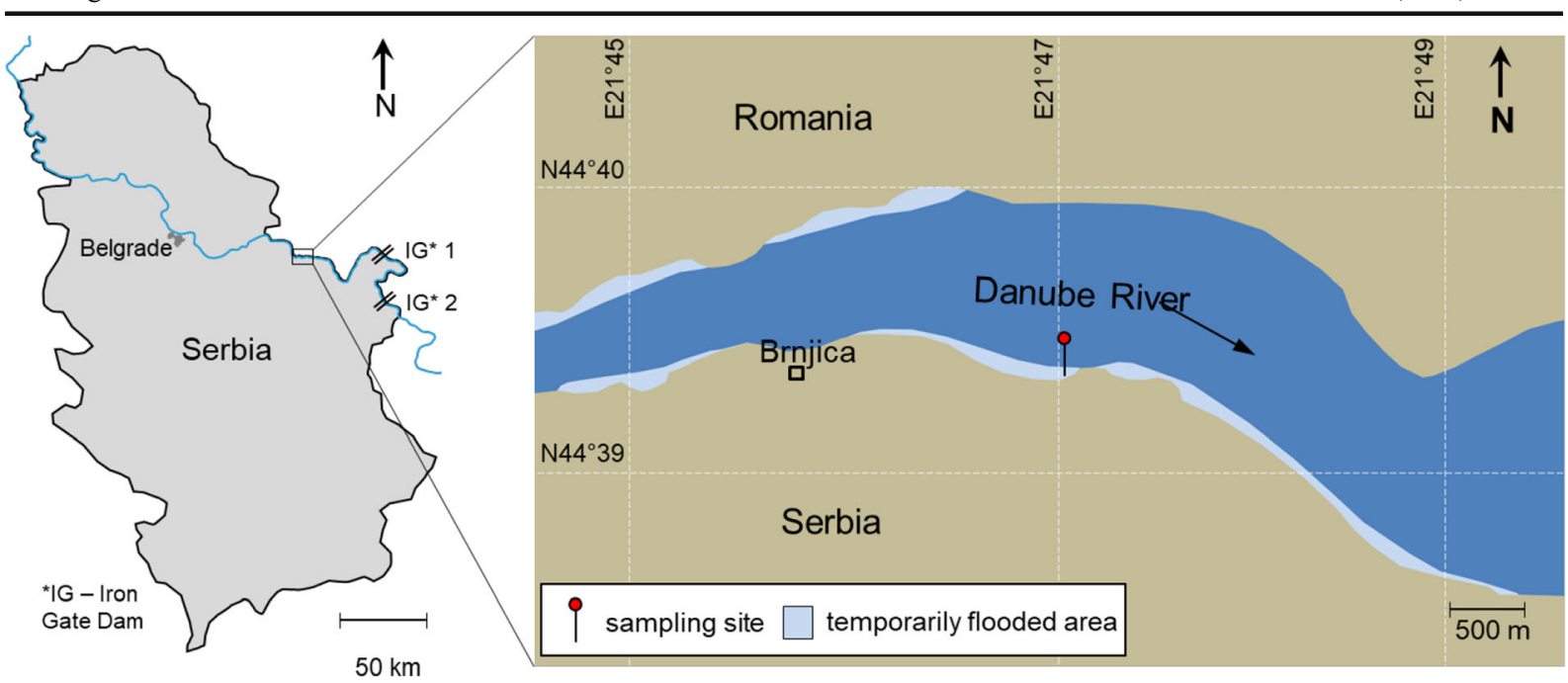

Fig. 1 Schematic sketch of the working area at the Serbian river section of the Danube River, and the positions of the sampling location 